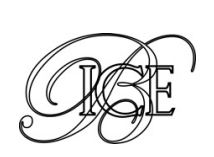

\title{
EVOLUCIÓN Y ANÁLISIS DE LA IDE ESPAÑOLA A TRAVÉS DE LA EMPRESA MULTINACIONAL
}

El presente artículo hace un repaso histórico al comportamiento de los flujos de inversión directa española por medio de las empresas multinacionales españolas. Se podrá diferenciar una serie de etapas en la evolución de la inversión directa extranjera española, caracterizada por su acumulación en Latinoamérica en la década de los noventa y en Europa en la primera década del nuevo siglo. Todos y cada uno de los datos están contrastados con ejemplos prácticos para dotar de más realidad y credibilidad a los aportados por las diferentes tablas y gráficos.

Palabras clave: IDE, empresa multinacional, offshoring, fusiones y adquisiciones, filiales, multinacional española.

Clasificación JEL: F21, F23, G34.

\section{Introducción}

La inversión directa extranjera (IDE) constituye la entrada neta de inversiones para obtener un control de gestión duradero (por lo general, un 10 por 100 o más de las acciones que confiere derecho a voto) de una empresa que funciona en un país que no es el del inversor. Es la suma de capital accionario, la reinversión de las ganancias, otras formas de capital a largo plazo y capital a corto plazo, tal como se describe en la balanza de pagos. Esta serie refleja el neto total, es decir, la IDE neta en la economía informante proveniente de fuentes extranjeras menos la IDE neta de la economía informante hacia el resto del mundo (Banco Mundial, 2015).

En la definición de inversión directa extranjera se da el hecho de que lleva consigo diferentes modalidades: filiales, greenfield investment, offshoring, international joint ventures y fusiones y adquisiciones

\footnotetext{
* Doctorando en Economía y Dirección de Empresas, Universidad de Alcalá de Henares.

Versión de marzo de 2015.
}

internacionales. Todas y cada una de ellas pueden orientarse tanto a la producción de bienes como a la prestación de servicios, incidiendo directamente sobre la economía del país receptor de la inversión. La creciente preocupación de los países por atraer este tipo de inversión por medio de políticas económicas y fiscales ha hecho que las mismas hayan incidido sobre el crecimiento y su competitividad y la del resto de países.

La IDE tiene el objetivo de generar un beneficio económico, medido a través de las exportaciones e importaciones de capital a largo plazo de los países, y estas se materializan en actividades empresariales. Las empresas que realizan este tipo de inversión se convierten en empresas multinacionales con gran relevancia en la producción internacional, en la generación y transferencia de tecnología, en la realización de alianzas estratégicas y en los acuerdos de cooperación internacionales, con impacto sobre las finanzas internacionales. Por medio de la IDE se logra internacionalizar tanto los capitales físicos como los financieros, así como $\triangleright$ 
los capitales inmateriales, comerciales, tecnológicos y los de índole empresarial (Durán, 2011).

\section{Evolución de la IDE española por medio de las empresas multinacionales}

\subsection{Las multinacionales españolas antes de 1990}

Los antecedentes históricos de la expansión de las empresas españolas se han de buscar en el abandono parcial de las políticas de sustitución de importaciones a favor de un crecimiento basado en la exportación. Las reformas económicas liberales iniciadas en 1959 dieron al capital extranjero el papel de complemento de la exigua tasa de ahorro nacional, propiciando la llegada masiva de divisas fuertes, que en aquellos años eran muy necesarias, y facilitaron la transferencia de tecnología (Varela Parache et al., 1974; Muñoz et al., 1978). La mayoría de los estudios realizados sobre este tema en concreto coinciden en que el Gobierno español de aquel entonces hizo poco para facilitar la inversión en el extranjero. El control del tipo de cambio era demasiado rígido y las subvenciones estatales para la creación de canales de distribución en mercados exteriores resultaron ineficaces (Varela Parache et al., 1972; Moreno Moré, 1975). El destino preferido de la inversión extranjera a principios y mediados de los setenta era el relativamente deprimido departamento francés de los Pirineos Orientales (el histórico Rosellón), al norte de Cataluña, una de las regiones industriales españolas más desarrolladas (Castellví, 1973; Raurich et al., 1973). Las empresas catalanas del sector textil, químico, alimentario, del vestido, los electrodomésticos y de bebidas invertían allí para asegurarse el acceso al Mercado Común Europeo, dado que el Acuerdo Preferencial, firmado por España en 1970, había fracasado en su intento de reducir los aranceles que gravaban las manufacturas intensivas en trabajo. Esta región en concreto fue elegida por su proximidad geográfica y sus costes laborales relativamente menores que los de otras zonas europeas.

La crisis económica mundial de 1973 y la transición a la democracia después de la muerte de Franco en 1975 ralentizaron la IDE en España. En cambio, en los últimos años de la década de los setenta, los flujos de inversión reanudaron su tendencia expansiva, aunque con importantes altibajos. A mediados de la década de los ochenta, esta trayectoria fue interrumpida, de nuevo, por la recesión mundial de 1981, consecuencia de la segunda crisis del petróleo, y por la incertidumbre inicial provocada por la victoria del Partido Socialista Obrero Español (PSOE) en las elecciones de 1982. En 1985 la IDE realizada representaba el 0,16 por 100 del PIB español, y la recibida el 1 por 100. Ambas tasas triplican las de principios de los setenta. Los cambios de la política del Gobierno propiciaron, en parte, esta tendencia alcista que había comenzado a mediados de la década de los setenta. Las instituciones, que desde 1940 habían ejercido un férreo control sobre las transacciones con el extranjero, fueron desmanteladas cuando el Ministerio de Comercio asumió el control y la autoridad sobre las inversiones extranjeras (de Erice, 1975).

Entre 1973 y 1977 se llevaron a cabo otras medidas importantes encaminadas a la simplificación y clarificación de los procedimientos para invertir en España (Muñoz et al., 178), mientras que a su vez se introdujeron cambios similares con respecto a la IDE española en el extranjero, como la redacción del primer texto integral que regulaba la inversión española en el exterior en 1973 y la firma de diversos decretos liberalizadores económicamente en 1978 (de Erice, 1975; Marín, 1982).

Durante la década de los ochenta las multinacionales españolas alcanzaron la mayoría de edad, periodo marcado por la liberalización económica en el ámbito de la Unión Europea, el rápido crecimiento económico, la expansión de la empresa privada tanto en la industria como en los servicios y la llegada a España de grandes flujos de inversión entre otros hechos. La adhesión a la UE propició $D$ 
que la IDE que tenía como origen y destino a otros países miembros se duplicase hasta convertirse, prácticamente, en dos tercios del total (Secretaría de Estado de Comercio, 1993). La incorporación de España a la Comunidad Económica Europea el 1 de mayo de 1986, supuso un acontecimiento político y económico de una relevancia posiblemente equivalente al Plan de Estabilización. A partir de ese momento, y en cierta medida en años previos, comenzó un cambio institucional dirigido hacia la eficiencia, viéndose ampliado al espacio económico de actuación de la empresa en un marco más competitivo, lo que supuso un esfuerzo de modernización productiva e inversión en I+D+i. El volumen de inversión directa emitida hacia el exterior, aunque relevante, seguía siendo inferior a la recibida. En el año previo a la incorporación a las instituciones europeas, el stock de inversión directa recibida representaba un 5,2 por 100 del PIB español, mientras que la emitida se situaba en el 2,6 por 100. Las inversiones procedentes de Estados Unidos y los países latinoamericanos disminuyeron en términos relativos, mientras que países como Francia, Países Bajos, Portugal y Marruecos se convirtieron en destinos cada vez más populares entre las empresas españolas.

\subsection{Las IDE de empresas españolas durante la década de los noventa: América Latina, principal receptor}

Durante la década de los noventa, la internacionalización de las empresas españolas se caracterizó por la concentración geográfica de sus inversiones en América Latina. Además de su cercanía cultural y la relación histórica entre España y la región, fueron una serie de cambios acontecidos en ella los que impulsaron la recepción de inversión procedente principalmente de las empresas españolas. En América Latina se abandonó el modelo de industrialización sustitutiva de importaciones para ejecutar las reformas estructurales, que bajo los auspicios del denominado Consenso de Washington permitirían superar la crisis del anterior modelo de desarrollo que desembocó en la pérdida productiva y económica de la década de los ochenta.

En general, los programas de ajuste emprendidos indujeron en la década de los noventa a una mayor estabilidad macroeconómica, una mayor disciplina fiscal, mayor fiscalización, mayor apertura exterior y un menor tamaño del Estado. Asimismo, la legislación sobre inversión extranjera empezó a ser más favorable y flexible para la captación de capitales foráneos (mejora en los procedimientos administrativos, menores restricciones a la repatriación de beneficios, menor número de sectores restringidos...), lo que se reflejó en una mejora del índice riesgo-país. Dentro de los ajustes, los procesos de privatización y de liberalización económica de sectores tradicionalmente protegidos llevados a cabo en los países de la región fueron el principal motivo de atracción de capital extranjero, lo que hizo que sus economías empezaran a recuperarse. Fue la segunda ola de estas privatizaciones, llevadas a cabo en la segunda mitad de la década de los noventa, sobre los sectores ligados con la prestación de servicios públicos (educación, sanidad y fondos de pensión) o en manos de los respectivos Gobiernos en régimen de monopolios (telecomunicaciones, energía eléctrica, hidrocarburos, distribución de aguas, servicios bancarios...), la que originó las grandes oportunidades de inversión aprovechadas por las empresas españolas. Las ventajas de localización fundamentales para el tejido empresarial español (tales como la oportunidad de producir para el mercado local, su tamaño y el potencial de crecimiento y la existencia de un idioma y cultura común) estuvieron ligadas al mercado local. Estos atractivos se hicieron más evidentes para las pequeñas y medianas empresas, las que suministraban actividades de servicios, las empresas de servicios y las que realizan poco esfuerzo innovador.

Tradicionalmente la internacionalización de la economía española en la región ha estado asociada a grandes operaciones en las que han $D$ 


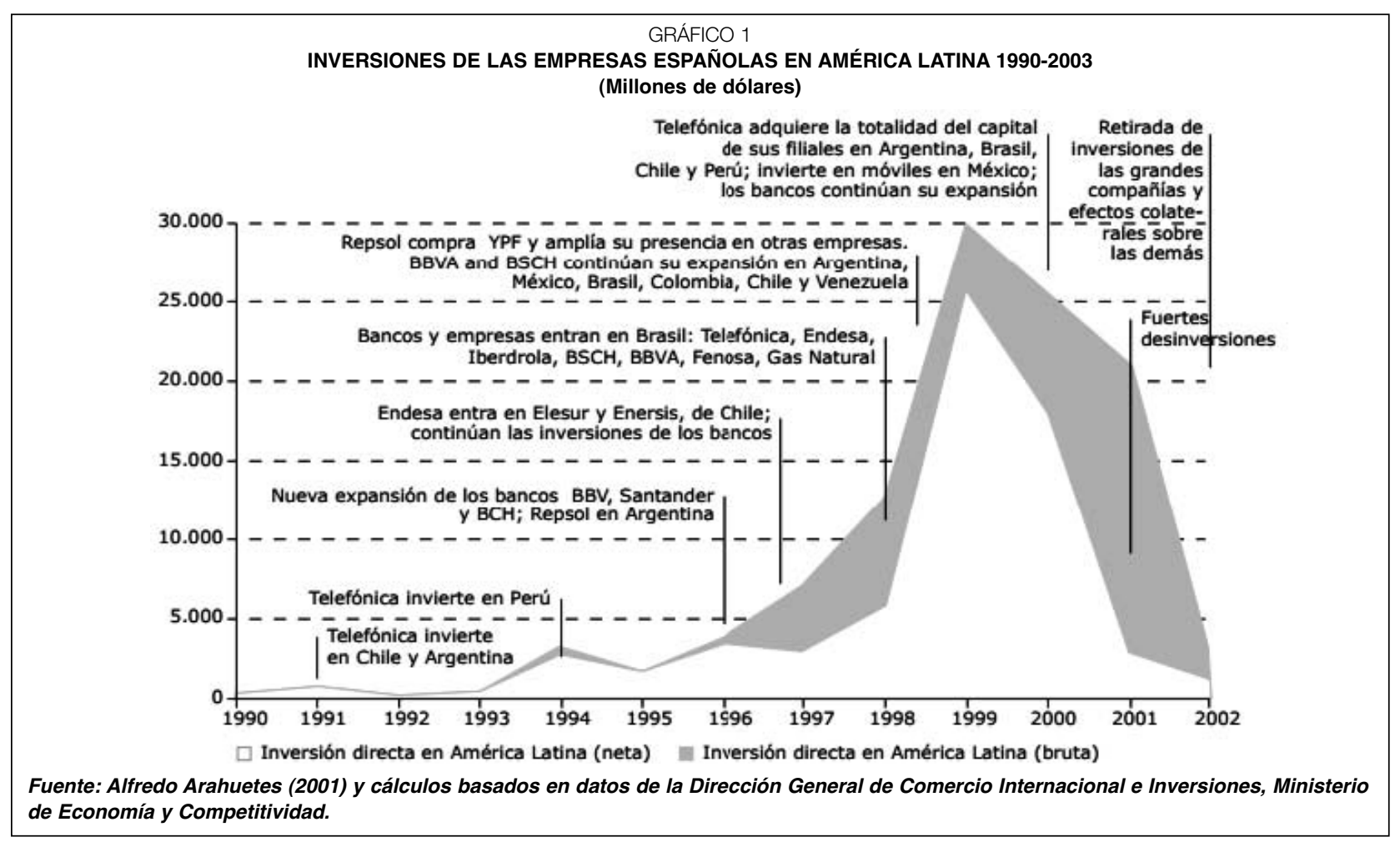

participado un número escaso de empresas españolas, como puede verse en el Gráfico 1. Entre las operaciones más importantes llevadas a cabo durante la década de los noventa del siglo pasado destacan la adquisición de YPF por parte de Repsol en 1999, la compra de Telefonía Peruana por parte de Telefónica en 1994 y 1996, así como parte del sistema Telebras en 1998, y el control de Enersis y de Codensa por parte de Endesa en 1997. En el caso de la energía eléctrica, la internacionalización estuvo marcada por la caída de los rendimientos de la actividad que se derivaban de la existencia de mercados maduros y crecientemente competitivos. Existen diferencias estratégicas entre las principales empresas del sector. Endesa, de forma mayoritaria, ha penetrado durante esta década en los mercados latinoamericanos a través de compras de activos que se privatizaban o de activos privados (previamente privatizados) con la característica esencial de la adquisición de Enersis, que contaba ya con presencia en otras economías latinoamericanas; Iberdrola, aunque sin desechar estas modalidades destacó por la instalación de nueva capacidad generadora, en especial en México; y Unión Fenosa, a través de Ufacex, se ha concentrado en las operaciones de consultoría ligadas al negocio de la energía eléctrica.

En el caso del petróleo, la internacionalización estuvo protagonizada, como se ha mencionado anteriormente, por la macro operación de la adquisición de YPF por parte de Repsol en 1999. El objetivo de esta operación fue aumentar el peso de las actividades de producción y refino que tenían, hasta ese momento, una importancia relativamente menor en Repsol.

El mercado argentino pasó a ser la base de la expansión de la empresa hacia las economías próximas, como Brasil o Chile, a través de intercambios de activos y nuevas inversiones. Por su parte, la internacionalización del sector financiero respondió a la caída de la rentabilidad de los servicios financieros en el mercado español como consecuencia de los menores ingresos que se derivaron de la prestación de servicios con menores comisiones, pagos por transferencias y la disminución de los tipos de interés asociados a la consolidación de la unión monetaria. El principal mecanismo de $\triangleright$ 
entrada fue la adquisición de bancos privados locales (latinoamericanos) casi siempre de reconocido prestigio y con una clientela fiel. Las dos principales entidades españolas siguieron estrategias diferentes. Mientras que el Banco Santander decidió primar la propiedad mayoritaria sobre las inversiones en el área, el BBVA llevó a cabo una estrategia de control de la gestión por medio de acuerdos con socios locales (Calderón y Casilda, 1999). Lo que ambas empresas tienen en común fue su estrategia de entrada a mercados de tamaño medio (Chile, Argentina, Colombia y Perú) para posteriormente realizar la entrada en mercados mayores como México y Brasil.

Cabe mencionar especialemente que se ha comprobado la escasa vinculación existente entre los citados sectores inversores (financiero, telecomunicaciones y energía) y los sectores exportadores, que tienen como primeros exponentes los bienes de equipo, las semimanufacturas, la industria agroalimentaria y los bienes de consumo. La alta participación de pymes en la exportación española es también otra diferencia entre ambas fórmulas de internacionalización.

En lo que se refiere a nivel estratégico, en el caso español existen claros ejemplos de penetración en lberoamérica que responden a las estrategias genéricas de las empresas en un proceso de internacionalización en general. Existen ejemplos de empresas españolas que en gran medida se han internacionalizado siguiendo estrategias defensivas, bien de forma aislada o por medio de alianzas cooperativas con otras empresas nacionales o extranjeras. Bajo la presión de la competencia nacional e internacional, empresas como Inditex, Cortefiel, Pescanova o Feber responden a esta modalidad estratégica durante la década de los noventa. Desde el punto de vista de empresas que siguen una estrategia de internacionalización que responde a actitudes ofensivas se encuentran numerosos ejemplos, empresas para las que prima el sentido de la expansión por encima de la supervivencia. Así, Telefónica, Sol Meliá, Hoteles Tryp, Endesa, Agbar, Gas Natural, Iberdrola, Iberia,
Banco Santander y el BBVA responden a esta actitud ofensiva, ya que no sólo buscaban nuevos mercados, sino también fortalecer su ventaja competitiva.

Algunas empresas siguieron procesos multifocales o mixtos (Doz, 1986), es decir, adoptaron estrategias globales para algún producto o grupo de actividades (banca de negocios, transmisión de datos y servicios internacionales de telecomunicaciones), mientras que otros segmentos responden claramente a un enfoque multidoméstico (banca comercial, telefonía básica). En este contexto es de destacar la relevancia que tienen las estrategias de cooperación. También se puede tipificar la estrategia de la internacionalización de las empresas bien como el resultado de alianzas o de acuerdos de cooperación (consorcios, contratos y ofertas conjuntas) o bien como consecuencia de decisiones aisladas (respuestas oligopolísticas o de proveedor-cliente). Así, por ejemplo, la evolución seguida por el sector del automóvil conformó la multinacionalización de las empresas españolas de componentes (Ficosa, Irausa, Mondragón) en México, Brasil y Argentina. Desde el punto de vista de la relación proveedor-cliente se puede mencionar el efecto arrastre que produjeron Telefónica, Endesa o Gas Natural, por ejemplo, con otras compañías españolas (y filiales españolas de multinacionales), no sólo en las exportaciones, sino también a nivel de inversión directa en el extranjero, como es el caso de Cobra o Amper.

Asimismo, un nutrido grupo de empresas utilizó la internacionalización como respuesta a una creciente rivalidad en el mercado interior español, como son los casos de las empresas conserveras, las de servicios financieros y las de servicios a otras empresas.

\subsection{Las IDE de empresas españolas durante la primera década del siglo XXI: Europa principal receptor}

Durante los inicios de la década que dio comienzo al nuevo siglo, se produjeron en Europa $\triangleright$ 


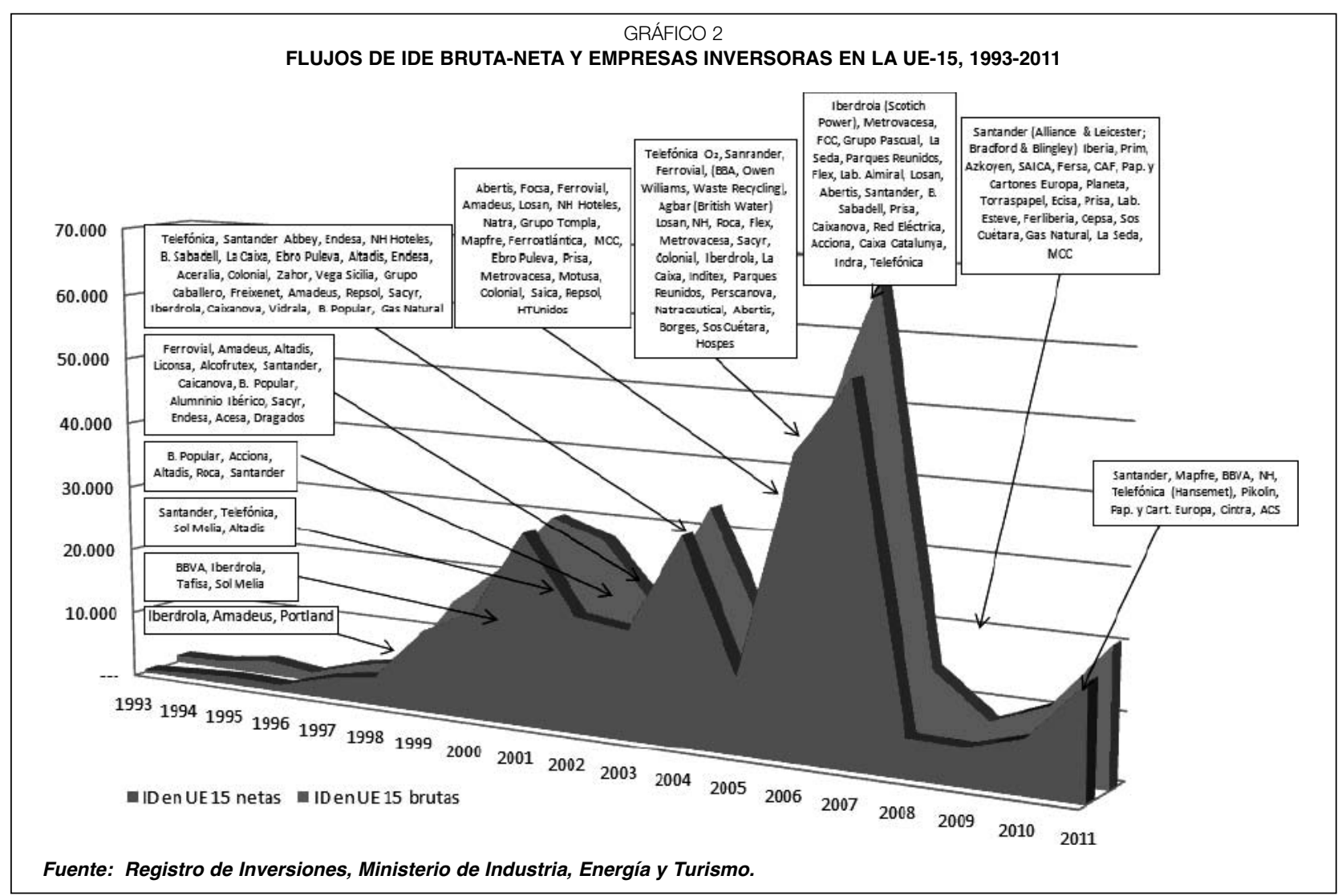

dos hechos que provocaron grandes cambios a nivel económico y empresarial y que cuyos efectos siguen aún vigentes a día hoy. Por un lado, la integración económica y monetaria europea (creación del euro y de la eurozona) y la entrada a la Unión Europea de países de Europa Central y del Este (en el año 2004 y 2007 con sendas ampliaciones) que vivieron desde la década de los noventa una transición hacia una economía de mercado desde los sistemas de planificación o socialismo de mercado.

Los países de Europa Occidental (UE-15) siguieron siendo los principales receptores de los flujos de inversión española, estrechando más los lazos empresariales existentes y consolidando las inversiones e intereses españoles en dichos países. Durante la etapa 2001-2011 se registraron importantes cambios en la orientación de la IDE y en el número de compañías que se incorporaron al proceso de internacionalización, que fue cada vez mayor. Las inversiones de las compañías españolas se dirigieron en esta ocasión en mayor medida a los países de la UE-15 (61 por 100), y a continuación se situaron América Latina (15 por 100), EEUU y Canadá (11 por 100), los países de la UE-12 ${ }^{1}$ (7 por 100), otros países europeos (4 por 100) y, en menor medida, China (0,75 por 100, incluido Hong Kong), Australia $(0,4$ por 100), la India (0,1 por 100) y en África, Marrue$\cos (0,5$ por 100$)$. La nueva gran oleada hacia los países de la UE-15 fue el resultado de las inversiones de grandes empresas (Gráfico 2) que realizaban destacadas operaciones de adquisición sobre todo en el primer grupo de países del área.

El perfil sectorial de las inversiones españolas en los países de la UE-15 muestra una alta concentración en actividades de servicios en telecomunicaciones e intermediación financiera, energía eléctrica y actividades comerciales, seguidas de industria química, otras manufacturas, infraestructuras, alimentación, bebidas y tabaco, otros servicios $\triangleright$

\footnotetext{
1 Integran este bloque de países los incorporados a la Unión Europea en el año 2004 (República Checa, Chipre, Eslovaquia, Eslovenia, Estonia, Hungría, Letonia, Lituania, Malta y Polonia) y en el año 2007 (Rumanía y Bulgaria).
} 
a empresas, servicios inmobiliarios, hostelería, papel e industria editorial e industria textil (Arahuetes, 2011).

Entre las operaciones más relevantes de inversión directa española en el continente europeo (principalmente en territorio británico) destacan las llevadas a cabo por las grandes multinacionales, tanto en volumen como en número de operaciones, lideradas por grandes operaciones de adquisición o de fusión. Destacan por encima de todas las adquisiciones realizadas por el Banco Santander (Abbey y Alliance \& Leicester en el Reino Unido; la filial comercial del Grupo SEB en Alemania), Telefónica (O2 en el Reino Unido), Ferrovial (BBA en el Reino Unido), Iberdrola (Scotish Power en el Reino Unido), Acciona (Pridesa en Alemania) y Agbar (British Water en el Reino Unido); y la fusión experimentada por Iberia (con British Airways, origen de IAG). Además de este tipo de inversiones, también se han efectuado inversiones mediante la implantación de filiales, como las pertenecientes a Colonial (SFL en Francia), Telefónica (O2 en el Reino Unido y Alemania) o Altadis (Logista en Portugal e Italia); mediante la apertura de puntos de venta u oficinas (Inditex y Mango en el sector textil; Mapfre en el sector asegurador; BBVA en el sector financiero); o por medio de la apertura de hoteles en el caso especial del sector turístico (NH, Sol Meliá).

Los países de la UE-12 fueron los cuartos destinatarios de las inversiones españolas, que se concentraron en Hungría, la República Checa, Polonia y Rumanía (OEME, 2010). Como se ha comentado anteriormente, este grupo de países pertenecía al bloque de la extinta Unión Soviética, caracterizados por tener economías planificadas que poco a poco se han transformado hasta tener economías de libre mercado. Ligado a los progresos en la implantación de las instituciones de una economía de mercado y a los logros en materia de liberalización de los mercados internos y de las transacciones con el exterior, se ha producido un gran número de procesos de privatización y reestructuraciones empresariales que ha incentivado la inversión directa extranjera en dichos países, dando lugar a una serie de deslocalizaciones industriales (offshoring), de la que también han sido partícipes las empresas españolas. Este hecho ha tenido mayor relevancia en los sectores tradicionales (industria textil, madera y corcho, fabricación de muebles y otras manufacturas), y de alto contenido tecnológico (fabricación de máquinas de oficina, equipos de informática y electrónicos, industria de material de transporte y fabricación de equipos e instrumentos de precisión).

Dentro del importante sector del material de transporte, despuntan los vehículos de motor (con más de 13 operaciones y 5.838 empleados afectados), con empresas deslocalizadas como Renault España, Seat o Ford, y la fabricación de partes, piezas y accesorios no eléctricos para vehículos de motor (más de 55 operaciones y un empleo afectado de más de 12.500 personas), donde las deslocalizaciones han recaído en empresas como Delphi Automotive, General Motors, Promek Magnetti Marelli (filial de Seat), Fycosa, SAS y Sysmo. En el segmento del material electrónico, mención especial merece la rama de válvulas, tubos y otros componentes electrónicos, encuadrada en las Tecnologías de la Información y la Comunicación (TIC), que representaron el 44 por 100 del total de operaciones registradas en ese sector y el 50 por 100 en términos de empleo. Aquí, las principales actuaciones han venido de la mano de firmas como Delphi (Cetasa, Packard) o Lear Corporation. En el ámbito del material eléctrico, sobresale, tanto por el número de operaciones como por empleo afectado, la rama clasificada por la CNAE como otro equipo eléctrico, en el que se incluyen actividades como el cableado para automóviles u otros sistemas eléctricos destinados fundamentalmente a la automoción, correspondiendo pues el grueso de la deslocalización a partes y piezas eléctricas para vehículos. Las empresas más influenciadas han sido Alcatel-Lucent Technologies y Ericsson.

En cuanto a la industria textil y de confección, sobresalen las de confección de prendas de vestir, textiles y de accesorios, que suponen el 46 por $\triangleright$ 
100 de las operaciones conocidas de deslocalización y el 51 por 100 del volumen de empleo dañado, destacando empresas como Sáez Merino, DB Appareal, Ferrys, Induyco y Tavex. Igualmente, las empresas de cuero y calzado (Kelme, Yanko, Pikolin entre otras) han deslocalizado sus actividades en dicha área, aunque sus mayores inversiones se produjeron en Marruecos y Asia. Por último, en el sector químico, despuntan Ercros, Myrurgia y Fertiberia, que han alternado Europa Central y del Este con China, mientras que entre las empresas de maquinaria y equipo mecánico, cabe señalar las desinversiones de Fagor y Zardoya-Otis.

\section{La IDE española: análisis sectorial y geográfico}

Aunque a niveles no muy relevantes, la inversión directa española en el exterior comienza a manifestarse de forma continuada desde la aparición del denominado Plan de Estabilización (de apertura exterior) de 1959. Desde esos momentos se perfila una distribución geográfica de su destino, ya que en ese período y subsiguientes muestra un cierto carácter estructural: más de las tres cuartas partes de esta inversión se dirige a América Latina (en primer lugar) y a Europa, seguida de África (principalmente países del Magreb) y EEUU.

Desde el punto de vista sectorial, hasta los ochenta, la inversión española en Iberoamérica se dirigió preferentemente a la fabricación de productos industriales (transformación de metales o mecánica de precisión), seguida del sector financiero y los sectores pesquero, agroalimentario y de la construcción. En cambio, los flujos de IDE en Europa lo fueron fundamentalmente en el sector comercio, como apoyo a las exportaciones (Durán y Sánchez, 1981). Como ya se ha indicado, desde un punto de vista sectorial, la inversión directa en la UE tiene un fuerte componente comercial, resultado de la actividad exportadora de la empresa española. Sin embargo, la presencia en Iberoamérica, área que presenta un menor nivel de desarrollo económico, es esencialmente de carácter industrial de una escasa intensidad tecnológica. En general, se aprecia una fuerte concentración en países geográficamente cercanos (Francia y Portugal) o culturalmente próximos, como es el caso de Latinoamérica.

En la primera mitad de los años ochenta se establecen políticas de saneamiento y ajuste económico (el nivel de desempleo supera el 10 por 100) y se negocia la adhesión a la Comunidad Económica Europea. El entorno económico internacional en esta etapa es favorable al proceso de integración europeo. El proceso de transformación estructural se acelera de manera significativa en la primera fase de integración (1986-1991), destacándose la relevancia de las inversiones en infraestructuras, en educación, en sanidad y en investigación y desarrollo. Asimismo, se produce una importante modernización de la empresa española ( $y$ de sus sectores de actividad) en un ambiente de competencia. En la Tabla 3 se ofrece la distribución geográfica y sectorial de la inversión directa española en el exterior de 1981 a 1990, diferenciando dos subperíodos. Así, en la primera mitad de los ochenta se observa que en el período precomunitario (1981-1985) América Latina sigue superando a la Unión Europea como receptor de IDE (destacando el sector secundario, 41,2 por 100), lo que contrasta con la primera etapa de la europeización, en la que la UE pasa a recibir aproximadamente un 54 por 100 del total, mientras que Latinoamérica se sitúa en el 9,5 por 100.

En el periodo 1986-1990 la inversión directa española dirigida a la UE supera en todos los sectores a la que recibe América Latina. Ahora bien, a partir de finales de este período (1989) se aprecia un cambio de modelo en la región latinoamericana. Se inicia un claro proceso de apertura exterior de las economías, acompañado de sendos programas de privatizaciones y de desregulación (liberalización), en los que se apuesta por el afianzamiento de los derechos de propiedad y por lograr una disciplina presupuestaria en contextos democráticos. 


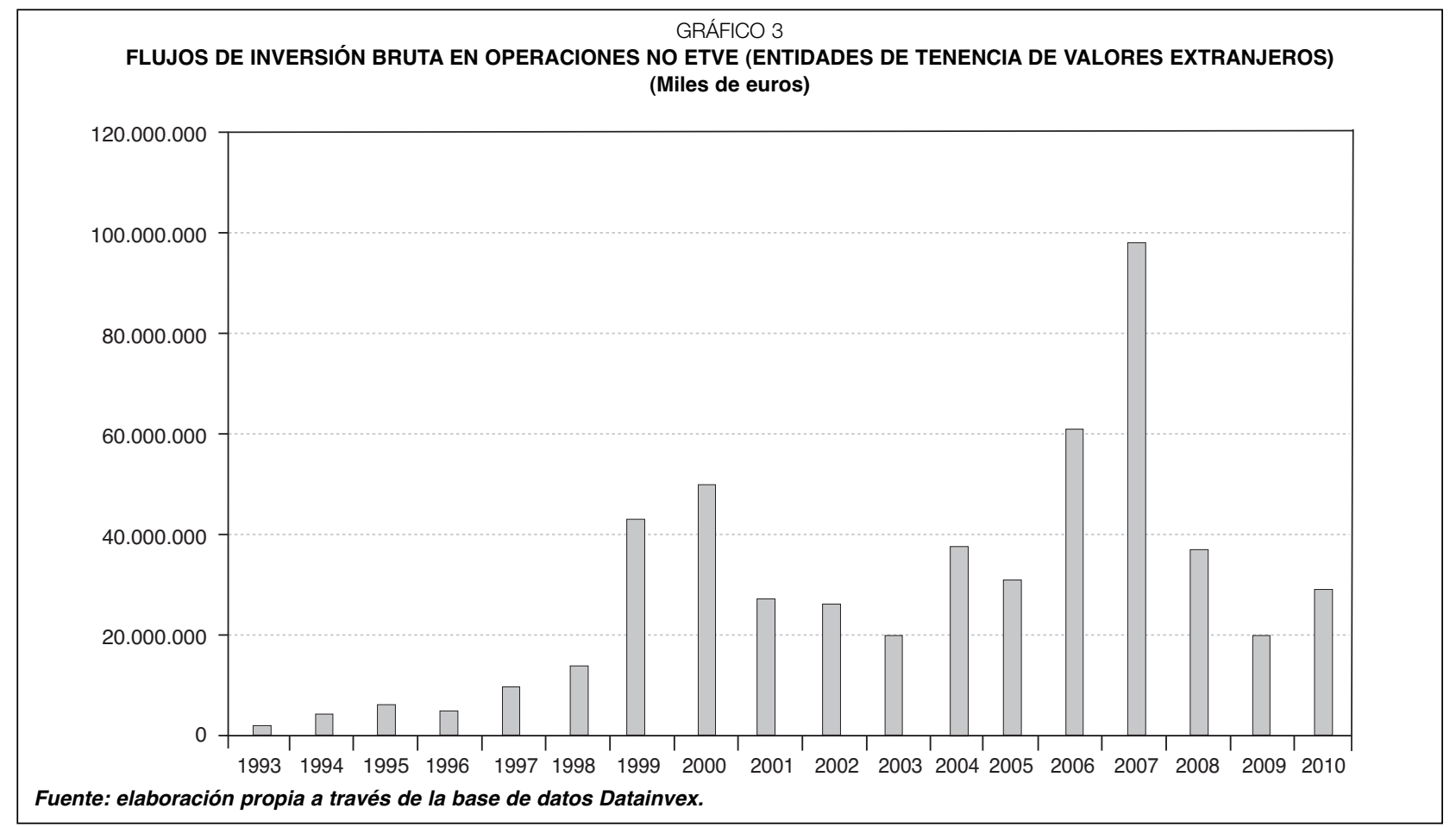

\begin{tabular}{|c|c|c|c|c|c|c|c|c|c|c|c|c|}
\hline \multicolumn{13}{|c|}{$\begin{array}{c}\text { TABLA } 1 \\
\text { DISTRIBUCIÓN GEOGRÁFICA Y SECTORIAL DE LA SALIDA D } \\
\text { (Valor porcentual) }\end{array}$} \\
\hline \multicolumn{13}{|c|}{ Servicios } \\
\hline & \multicolumn{2}{|c|}{ Primario } & \multicolumn{2}{|c|}{ Secundario } & \multicolumn{2}{|c|}{ Comercio } & \multicolumn{2}{|c|}{$\begin{array}{l}\text { Transporte y } \\
\text { comunicación }\end{array}$} & \multicolumn{2}{|c|}{ Financiero } & \multicolumn{2}{|c|}{ Total } \\
\hline & 1981-85 & $1986-90$ & 1981-85 & $1986-90$ & $1981-85$ & $1986-90$ & $1981-85$ & $1986-90$ & 1981-85 & $1986-90$ & 1981-85 & $1986-90$ \\
\hline Unión Europea....................... & 10,3 & 30,6 & 29,5 & 60,9 & 35,2 & 48,1 & 55,6 & 43,4 & 16,6 & 56,2 & 25,4 & 53,8 \\
\hline EEUU & 31,0 & 31,1 & 7,2 & 8,3 & 28,8 & 10,0 & 1,6 & 5,4 & 14,6 & 6,7 & 16,0 & 9,5 \\
\hline 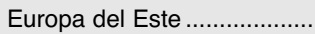 & 0,0 & 0,0 & 0,0 & 2,8 & 0,0 & 0,6 & 0,0 & 0,0 & 0,0 & 0,0 & 0,2 & 0,4 \\
\hline 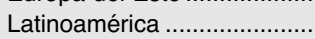 & 23,3 & 7,9 & 41,2 & 15,1 & 12,7 & 14,9 & 9,2 & 1,9 & 29,0 & 7,2 & 29,1 & 9,4 \\
\hline 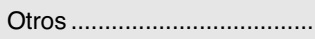 & 31,4 & 30,4 & 22,1 & 12,9 & 23,3 & 26,4 & 33,6 & 49,3 & 39,8 & 29,9 & 33,3 & 26,9 \\
\hline Total (\%) & 6,83 & 8,93 & 19,76 & 17,14 & 13,94 & 8,9 & 1,36 & 1,43 & 54,2 & 62,3 & - & - \\
\hline
\end{tabular}

Durante la última década del siglo $\mathrm{xx}$ casi un millar de empresas españolas realizaron inversiones importantes en el extranjero. Después de de aislamiento internacional y retraso, España entró en el siglo XXI como un país relativamente «normal y moderno", con un alto nivel de integración con el resto de economías mundiales que se consideran potencias mundiales. A partir de 1992, las empresas españolas respondieron a la creciente llegada de compañías extranjeras y a la creación de un mercado único europeo intensificando sus propias inversiones en el exterior, un proceso que llevó a una situación, a finales del año 2000, en la que España se caracteriza desde entonces por ser un emisor neto de flujos de inversión.

Como muestra el Gráfico 3, los flujos de inversión emitidos siguen una senda creciente durante toda la década de los noventa, con su cénit en los años 1999 y 2000 , donde el montante total de la inversión directa emitida fue de 42.845.297,72 miles de euros y 49.701.190,75 miles de euros respectivamente. Este incremento viene dado por las importantes operaciones efectuadas por Telefónica (19,8 miles de millones) y Repsol YPF (16,5 miles de millones), seguidas muy de lejos por Endesa (3,6 mil millones), el BBVA (3,3 mil millones) y el Banco Santander (2,7 mil millones de euros). 


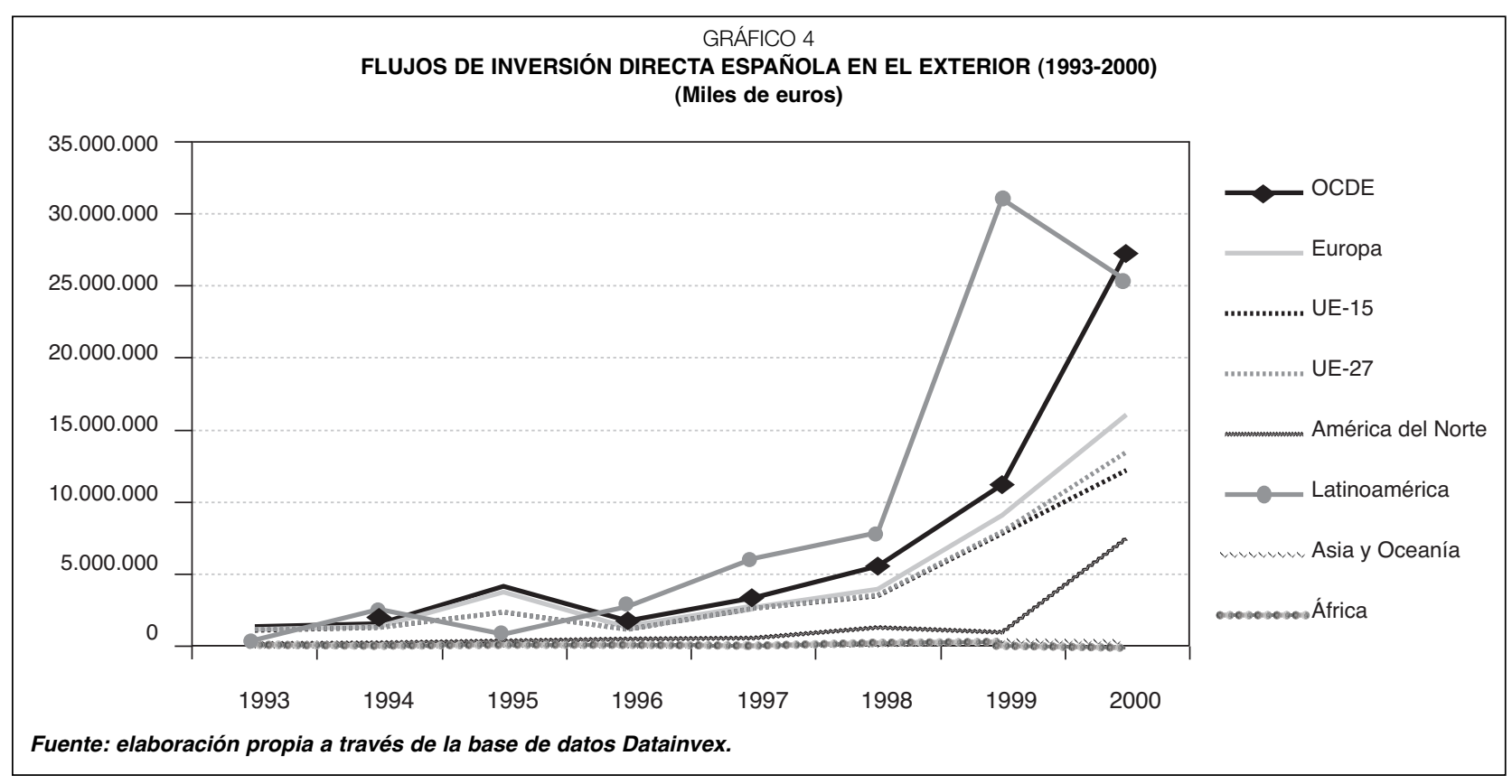

En la primera mitad de la primera década del siglo XXI, los flujos de inversión disminuyen en cuantía, pero se mantienen altos entre los $20 \mathrm{mil}$ millones y los 40 mil millones de euros, hasta que alcanzan su apogeo en los años 2006 y 2007, precisamente los dos años que preceden al inicio de la crisis mundial y española que se inició en 2008.

En 2006 el montante en euros de la inversión directa emitida alcanzó la cifra de 60,7 mil millones de euros, mientras que en 2007 la economía española vivió su apogeo internacional en cuanto a inversiones directas emitidas se refiere, con un total de 97,9 mil millones de euros. A pesar de la crisis económica mundial y española en especial, las inversiones directas españolas han seguido manteniendo un gran peso respecto al PIB entre 2008 y 2011, y su montante medio es incluso superior al de los años 2001-2005 (28,7 mil millones de euros frente a los 28,2 mil millones de euros). Esto se ha debido a que las empresas españolas han compensado el descenso de la demanda interna española con las ventas e ingresos producidos en otros países, ganando cada vez más peso los mercados internacionales en los balances de las empresas españolas.

Una muestra de ello y de la confianza que depositan las multinacionales españolas en los mercados internacionales son las diferentes inversiones que se han realizado en este período de crisis, sobre todo en los Estados Unidos, objetivo final de muchas empresas que iniciaron su andadura internacional en tierras latinoamericanas: Iberdrola ha invertido en tierras norteamericanas un total de 8 billones de dólares acorde con su plan estratégico US 2008-2010, incluyendo la compra de Energía East; Mapfre invirtió 2.000 millones de dólares en la compra de «The Commerce Grupo»; el Banco Santander adquirió Sovereign por 2.000 millones de dólares en 2008; BBVA compró Compass Bancshares por un total de 9.600 millones dólares en 2009 .

En la década de los noventa la preferencia española por los países latinoamericanos fue de nuevo la protagonista gracias a la solución de los problemas de créditos de las economías sudamericanas y mexicana, a los procesos de liberalización y privatización que caracterizaron a la región durante dicho periodo, al crecimiento económico experimentado por muchos de ellos y la cercanía cultural entre España y sus antiguas colonias. El Gráfico 4 muestra la tendencia de la IDE española emitida durante la última década del siglo xx. Como se aprecia claramente, Latinoamérica fue el principal destino de la inversión emitida, acumulando el 59,61 por 100 del total, mientras que Europa recibía el 30,45 por 100 . Por otro lado, Norteamérica $\square$ 


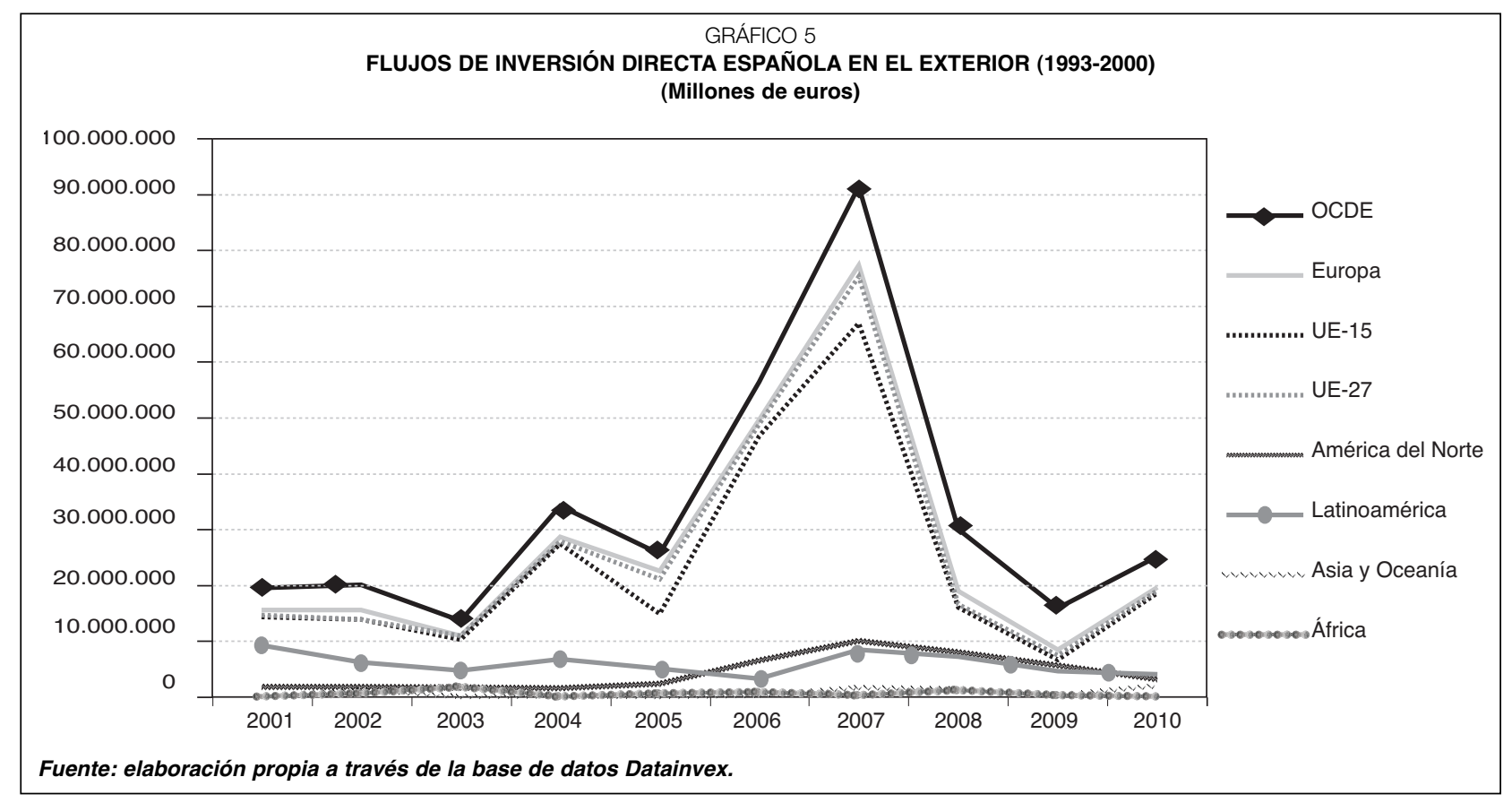

\begin{tabular}{|c|c|c|c|}
\hline \multicolumn{4}{|c|}{$\begin{array}{l}\text { TABLA } 2 \\
\text { PRINCIPALES SECTORES DE DESTINO DE LA IDE ESPAÑOLA (1993-2010) } \\
\text { (Inversión bruta en miles de euros) }\end{array}$} \\
\hline Código CNAE & Industria & Valor de la IDE & Cuota de la IDE española \\
\hline 64 & Servicios financieros & $263.584 .231,59$ & 50,77 \\
\hline 61 & Telecomunicaciones & $69.800 .984,04$ & 13,45 \\
\hline 35 & Suministros de energía eléctrica, gas, vapor y aire .............. & $35.692 .538,91$ & 6,87 \\
\hline 23 & Fabricación de otros productos minerales no metálicos..... & $32.449 .919,01$ & 6,25 \\
\hline 41 & 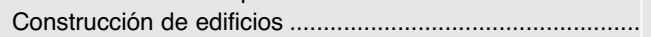 & $12.965 .477,03$ & 2,50 \\
\hline 20 & Industria química & $11.593 .619,68$ & 2,23 \\
\hline 46 & Comercio al por mayor e intermediación comercial............... & $9.637 .706,82$ & 1,83 \\
\hline 52 & Almacenamiento y actividades anexas al transporte ........... & $5.711 .184,25$ & 1,10 \\
\hline 29 & Metalúrgica, fabricación productos de hierro y acero ........... & $5.411 .024,50$ & 1,04 \\
\hline 47 & 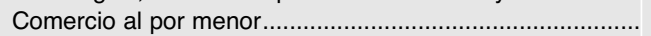 & $5.290 .514,69$ & 1,01 \\
\hline
\end{tabular}

(Estados Unidos y Canadá) era la tercera región en discordia, pero con un peso bastante bajo $(8,75$ por 100 del total de IDE) en comparación con las otras dos regiones vistas anteriormente. Las inversiones en el resto de mundo eran insignificantes, ya que la región Asia-Oceanía recibía el 0,614 por 100 y África el 0,562 por 100 del total de IDE española emitida al exterior.

En el año 2001 se produce un acontecimiento que marcará la década en cuanto a la tendencia de las inversiones directas emitidas en España: la entrada en funcionamiento de la zona euro. Así pues, entre 2001 y 2010, la IDE española se dirigió principalmente hacia las economías de los países de la
UE-15 (61,5 por 100), América Latina (14 por 100), EEUU y Canadá (11,5 por 100), los países de la UE-12 (7,2 por 100), otros países europeos (3,5 por $100) \mathrm{y}$, en menor medida, China $(0,72$ por 100 , incluido Hong Kong), Australia (0,35 por 100), la India $(0,1$ por 100$) y$, en África, Marruecos $(0,46$ por 100). Puede observarse la tendencia en el Gráfico 5.

A nivel sectorial, se puede observar en las Tablas 2 y 3 que tanto el origen como el destino de la mayoría de la IDE española tienen como protagonistas a las mismas industrias durante el periodo comprendido entre 1993 y 2010. Desde España, los flujos de inversión se han originado principalmente desde el sector financiero aportando $D$ 


\begin{tabular}{|c|c|c|c|}
\hline \multicolumn{4}{|c|}{$\begin{array}{l}\text { TABLA } 3 \\
\text { PRINCIPALES SECTORES DE DESTINO DE LA IDE ESPAÑOLA (1993-2010) } \\
\text { (Inversión bruta en miles de euros) }\end{array}$} \\
\hline Código CNAE & Industria & Valor de la IDE & Cuota de la IDE española \\
\hline 64 & 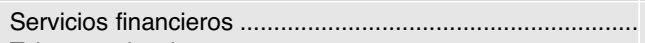 & $161.826 .112,24$ & 28,81 \\
\hline 61 & Telecomunicaciones & $99.500 .965,13$ & 17,71 \\
\hline 35 & Suministros de energía eléctrica, gas, vapor y aire .............. & $54.609 .013,13$ & 9,72 \\
\hline 23 & Fabricación de otros productos minerales no metálicos..... & $23.583 .809,98$ & 4,19 \\
\hline 06 & Extracción de crudo de petróleo y gas natural ..................... & $18.534 .875,93$ & 3,29 \\
\hline 46 & Comercio al por mayor e intermediación comercial .............. & $17.762 .391,05$ & 3,16 \\
\hline 41 & Construcción de edificios . & $16.851 .092,72$ & 3,00 \\
\hline 65 & Seguros, reaseguros y fondos de pensión ………............ & $14.404 .246,82$ & 2,56 \\
\hline 52 & Almacenamiento y actividades anexas al transporte........... & $12.051 .330,18$ & 2,14 \\
\hline 24 & Metalúrgica, fabricación productos de hierro y acero .......... & $11.658 .673,48$ & 2,07 \\
\hline
\end{tabular}

\begin{tabular}{|c|c|c|c|}
\hline \multicolumn{4}{|c|}{ 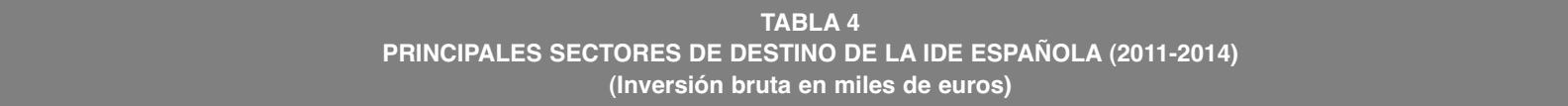 } \\
\hline Código CNAE & Industria & Valor de la IDE & Cuota de la IDE española \\
\hline 64 & 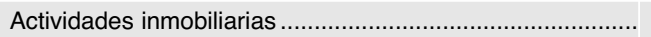 & $6.370 .662,23$ & 9,70 \\
\hline 61 & 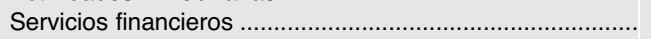 & $6.243 .226,81$ & 9,56 \\
\hline 35 & 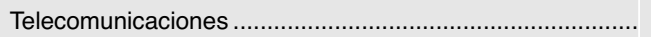 & $5.864 .699,41$ & 8,99 \\
\hline 23 & Comercio al por mayor e intermediación comercial............... & $4.835 .372,29$ & 7,46 \\
\hline 06 & 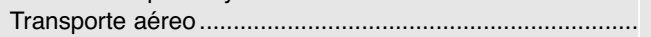 & $4.110 .297,37$ & 6,32 \\
\hline 46 & Suministro de energía eléctrica, gas, vapor y aire ............... & $3.841 .768,91$ & 5,87 \\
\hline 41 & Metalúrgica, fabricación productos de hierro y acero ........... & $2.776 .506,32$ & 4,24 \\
\hline 65 & 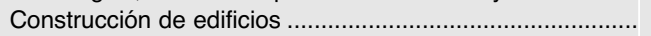 & $2.325 .379,78$ & 3,59 \\
\hline 52 & Actividades auxiliares a los servicios financieros ................... & $2.034 .119,04$ & 3,11 \\
\hline 24 & Fabricación de otros productos minerales no metálicos..... & $1.987 .122,80$ & 3,01 \\
\hline
\end{tabular}

más del 50 por 100 de los mismos, en donde las grandes operaciones financieras de los principales bancos españoles han influido en este dato. Tras dicha industria se encuentra el sector de las telecomunicaciones, con casi el 13,45 por 100 del tráfico de flujos emitidos desde España.

Otros sectores importantes son el de suministros de energía eléctrica, gas, vapor y aire $(6,87$ por 100), la fabricación de otros productos minerales no metálicos (6,25 por 100), la construcción de edificios (2,50 por 100) y la industria química $(2,23$ por 100$)$. Desde el punto de vista de las industrias extranjeras que han sido el destino de la IDE española durante el periodo de 19932010 , destaca el sector financiero, con un 28,81 por 100 del total, por lo que se intuye que ha habido inversiones de diversificación por parte del sector financiero español en exterior.

Las telecomunicaciones, al igual que en origen, ocupan el segundo puesto como industria receptora de la inversión española, con un montante total y en porcentaje mayor que como originario $(17,71$ por 100$)$. Tras ellos, tiene importancia la industria de suministros de energía eléctrica, gas, vapor y aire (9,72 por 100), la fabricación de otros productos minerales no metálicos (4,19 por 100$)$ y la extracción de crudo de petróleo y gas natural $(3,29$ por 100$)$.

\section{Situación actual}

A pesar de que la crisis ha incentivado a muchas empresas a salir al exterior, si atendemos a las cifras dadas por el ICEX, las inversiones directas extranjeras presentan una tendencia a la baja (Gráfico 6), patrón de comportamiento comenzado en 2008. A pesar de que en 2009 parecía mostrarse una tendencia alcista, sólo fue un espejismo, puesto que las cifras muestran lo contrario, para todos los destinos.

El montante total de euros de la IDE española en la actual década alcanza los 65.248.192,78 miles $\triangleright$ 


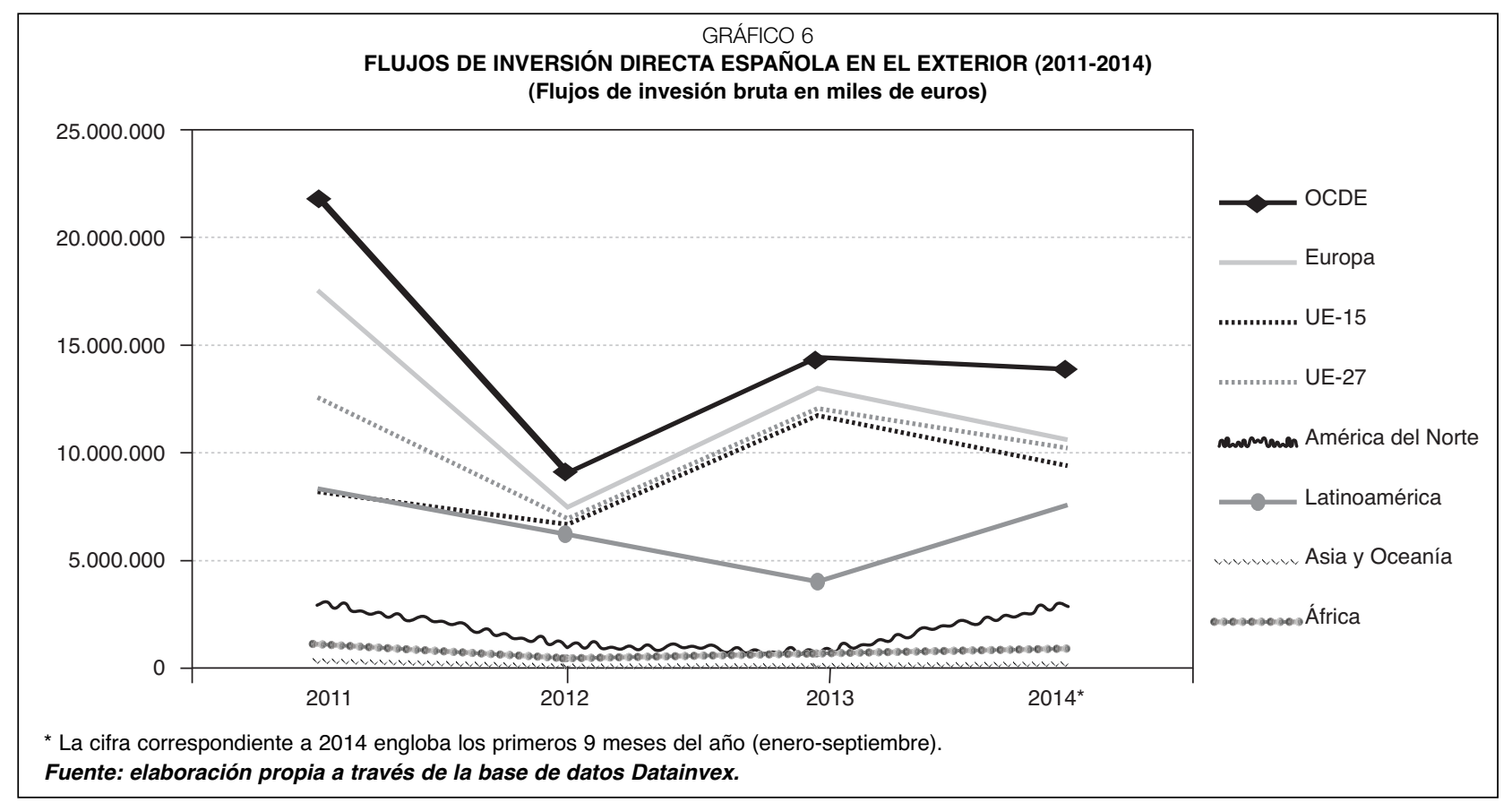

de euros, siendo los países de la zona monetaria (UE-15) los principales destinos de la inversión, ya que los mismos están a su vez incluidos en el segmento de países pertenecientes a la OCDE. Además, las cifras recogen el hecho cada vez más común del alza de las inversiones españolas en Norteamérica ( $1.769 .746,30$ miles de euros) y en países de la zona Asia-Pacífico (1.998.465,176 miles de euros), tendencia contraria a la que sufren los países latinoamericanos.

En lo que se refiere al sector origen de la inversión directa extranjera española, las actividades financieras es el sector más activo a nivel internacional, ya que si sumamos las actividades auxiliares para la realización de las mismas acumulan un montante de 6.574.081,27 miles de euros. Además, puede contemplarse que otros sectores que han sufrido directamente el impacto de la crisis española se encuentran entre los que más buscan en los mercados internacionales una diversificación de sus actividades y riesgos, como son las actividades inmobiliarias y la construcción de edificios.

Actividades relaciones con las telecomunicaciones, el comercio al por mayor e intermediación comercial, el suministro de energía eléctrica, gas, vapor y aire, metalurgia, fabricación de productos hierro y acero y otros minerales no metálicos siguen siendo a pesar de la crisis los sectores que más fuerte apuestan por la internacionalización mediante inversiones directas extranjeras.

\section{Conclusiones}

Los flujos de inversión directa extranjera española han ido creciendo a partir de la década de los noventa, observándose dos claras dinámicas de crecimiento. La primera de ellas tuvo lugar en la década de los noventa y su orientación geográfica estaba en los países latinoamericanos, en gran parte por su cercanía cultural y relación histórica con España, así como por las políticas de liberalización y privatización de muchas economías latinoamericanas. La segunda de las dinámicas tiene un marcado rasgo europeo, y se produce desde la entrada en vigencia del euro en la eurozona.

Por otro lado, se observa que desde el inicio de la crisis financiero-económica mundial y española, el volumen de los flujos de inversión españoles ha disminuido considerablemente, siendo no obstante un medio para empresas pertenecientes a los sectores que más han sufrido la crisis (sector financiero, inmobiliario, construcción de edificios) $\triangleright$ 
para generar nuevos ingresos y diversificar los riesgos.

\section{Biblibliografía}

[1] BOURGUIGNON, F. et al, (2002). «Making sense of Globalization», CEPR Policy Paper, 8.

[2] CANALS, C. y NOGUER, M. (2007). «La inversión extranjera directa en España: ¿qué podemos esperar del tigre celta?». Documento de Economía de la Caixa, n 7, pp. 5-29.

[3] CÁMARAS DE COMERCIO DE ESPAÑA (2007). «Internacionalización de la empresa española. Cooperación Empresarial e Inversión exterior». Madrid.

[4] CHISLETT, W. (2003). «La inversión española directa en América Latina: retos y oportunidades». Real Instituto Elcano de Estudios Internacionales y Estratégicos. Madrid.

[5] DE MATÍAS BATALLA, D. (2015). «Debe ser revisado el paradigma ecléctico ante las nuevas formas de hacer negocios internacionales?». Revista de Informacion Comercial Española, $\mathrm{n}^{\circ}$ 3060, pp. 39-50.

[6] DÍAZ VÁZQUEZ, R. (2003). «Las teorías de la localización de la inversión extranjera directa: Una aproximación». Revista Gallega de Economía, vol. 12, no 1, pp. 1-12.

[7] DUNNING, J.H. (1994). «Re-evaluating the benefits of foreign direct investment», Journal of International Business Studies, $\mathrm{n}^{\circ}$ 26, pp. 461-491.

[8] DURÁN HERRERA, J.J. (2000). «La inversión extranjera en el siglo $\mathrm{xx}$. La persistente multinacionalización de la empresa", Revista de Economía Mundial, $n^{\circ}$ 3, pp. 121-148.

[9] DURÁN HERRERA, J.J. (2003). "Veinticinco años de inversión directa española en el exterior, 1978-2003: una senda de crecimiento". Economía Industrial, ${ }^{\circ} 350$, pp. 147-154.

[10] DURÁN HERRERA, J.J. et al., (2007). «Inversión directa en el exterior, crecimiento económico y exportaciones de la economía española», Revista de Informacion Comercial Española, nº 839, pp. 35-54.

[11] ESRC CENTRE FOR BUSINESS RESEARCH (2008). «FDI, the location advantages of countries and the competitiveness of TNCS: US FDI in professional service industries". Working Paper, $\mathrm{n}^{\circ}$ 128. University of Cambridge.
[12] FERREIRO, J. GÓMEZ, J. y RODRÍGUEZ, C. (2009). Estabilidad de los flujos de inversión extranjera directa: el caso de las inversiones españolas en Latinoamérica, Departamento de Economía Aplicada V, Universidad del País Vasco.

[13] FMI (2008). «International Investment Position», capítulo 7 del informe Balance of payments and international investment position manual. New York.

[14] GALÁN, J.I. y GONZÁLEZ, J. (2001). «Factores explicativos de la inversión directa española en el exterior», Revista de Informacion Comercial Española, $\mathrm{n}^{\circ}$ 794, pp. 103-122.

[15] GALÁN, J.I., GONZÁLEZ, J. y ZÚÑIGA, J. (2007). «Factors determining the location decisions of Spanish MNEs: An analysis based on the investment development path». Journal of International Business Studies, , vol. 38, n 6, pp. 975-997.

[16] ICEX (2010). «Internacionalización, empleo y modernización de la economía española». Madrid.

[17] LÓPEZ, C. y GARCÍA, E. (2002). «La inversión directa de las empresas españolas en Latinoamérica». Revista Asturiana de Economía, $\mathrm{n}^{\circ} 23$, pp.27-45.

[18] OBSERVATORIO DE LA EMPRESA MULTINACIONAL ESPAÑOLA (2008). «La expansión de la multinacional española: estrategias y cambios organizativos». Madrid.

[19] RODRíGUEZ, C. GÓMEZ, C. y FERREIRO, J. (2005). «Panorámica de los estudios sobre inversión extranjera directa». Ekonomia, n 55, pp. 284-301.

[20] RONDEROS, C. (2010). «Inversión extranjera y competitividad». Revista Globalización, Competitividad y Gobernabilidad - GCG. Georgetown University, vol. 4, no 2, pp. 72-87.

[21] SANTISO, J. (2007). «La internacionalización de las empresas españolas: Hitos y retos", Revista de Informacion Comercial Española, $\mathrm{n}^{\circ}$ 839, pp. 89-102.

[22] SIERRA FERNÁNDEZ, M.P. (2007). «Estrategias de internacionalización de la gran banca española» Pecvnia, $n^{\circ}$ 5, pp. 229-272.

[23] VALDEMORO, M.J.; GUILLÉN, M.F. y GRANDAL, M. (2010). «Anuario 2010. Internacionalización de la empresa española». Wharton University of Pennsylvania. 
